\title{
Choledochal Cysts Diagnosis and Treatments: Case Report
}

\author{
Mohamed Noaman Al-Ba'adani ${ }^{1}$, Saleh Ahmed Alammari ${ }^{1}$, Najwa Aziz Jumman ${ }^{2}$ \\ ${ }^{1}$ Surgery Department, Al-Gomhory Teaching Hospital, Sana'a, Yemen \\ ${ }^{2}$ MBBS University of Science and Technology, Sana'a, Yemen \\ Email:dmohammedalbadani@gmail.com
}

How to cite this paper: Al-Ba'adani, M.N., Alammari, S.A. and Jumman, N.A. (2022) Choledochal Cysts Diagnosis and Treatments: Case Report. Open Access Library Journal, 9: e7382.

https://doi.org/10.4236/oalib.1107382

Received: January 8, 2022

Accepted: February 18, 2022

Published: February 21, 2022

Copyright ( 2022 by author(s) and Open Access Library Inc.

This work is licensed under the Creative Commons Attribution International License (CC BY 4.0).

http://creativecommons.org/licenses/by/4.0/ (c) (i) Open Access

\begin{abstract}
Choledochal cyst is a rare pathological condition, which represents $1 \%$ of benign diseases of the biliary tract. It is seen with significant frequency in childhood, with a higher prevalence in females. Diagnosis is primarily based on clinical suspicion. Its symptoms are variable and its treatment, depending on the type, is surgical. Case Report: A 5-year-old female childhood, weighing $20 \mathrm{~kg}$ presented with a two weeks history of upper abdominal pain, jaundice and low-grade fever for 8 days, accompanied by high colored urine, and pale colored stools. Our case diagnosis was made by biochemical parameters and ultrasonography, CT-scan. The recurrent cholangitis, pancreatitis and malignant diseases associated with choledochal cysts mandate early diagnosis and definitive surgical management.
\end{abstract}

\section{Subject Areas}

Oncology, Surgery \& Surgical Specialties

\section{Keywords}

Choledochal Cyst, Bile Duct Cyst

\section{Introduction}

Choledochal cysts are congenital abnormalities of the biliary system and consist of cystic dilatations of the extrahepatic biliary tree, intrahepatic biliary ducts or both. The incidence of choledochal cyst in western countries has been reported to be 1:100,000 to 1:150,000 [1]. Females are affected two to four times more often than males. The clinical classification, which describes five different types and subtypes, was revised in 1977 by Todani and colleagues [2]. The most common cystic dilatation is type I with diffuse or segmental fusiform dilatation of 
the common bile duct. This type accounts for $50 \%$ to $85 \%$ of cases. Type I cysts should be considered in the differential diagnosis of any patient with ductal dilatation. The leading symptoms include cholestatic jaundice and abdominal pain. A palpable abdominal mass occurs in less than $20 \%$ of the cases. In adults, chronic and intermittent abdominal pain is the most common symptom. Recurrent cholangitis and jaundice may also occur. A choledochal cyst is rarely symptomatic, but should be considered if dilatation of the bile duct or the ampulla is demonstrated. The main diagnostic tool for detection of a choledochal cyst, especially in childhood, is ultrasonography. In adults, computer tomography can confirm the diagnosis; however, endoscopic retrograde cholangiography and magnetic resonance cholangiography are the most valuable diagnostic methods and can accurately show cystic segments of the biliary tree [3]. Surgery is the treatment of choice for a choledochal cyst. Complete excision of all cystic tissue is recommended because of the risk of recurrent cholangitis and the high risk of malignant degeneration [4]. Excision of the cyst and reconstruction of the biliary tree by choledochal hepato-jejunostomy with a Roux-en Y-loop is the standard procedure [5]. We had a 5-year-old female child with choledochal cyst under our care, whose findings and management are reported here.

\section{Case Presentation}

A 5-year-old female childhood, weighing $20 \mathrm{~kg}$ presented with a two weeks history of upper abdominal pain, jaundice and lowgrade fever for 8 days, accompanied by high colored urine, and pale colored stools. No history of blood transfusion, any drug ingestion was found. Clinical examination revealed deep icterus. Liver was palpable; size was 2 fingers below costal margin, surface was smooth and non-tender. There was an ill-defined lump about $(8 \times 5) \mathrm{cm}$ palpable in the right hypochondrium, which was also non-tender and was not moving well with the respiration. No free fluid in the abdomen or any signs of liver cell failure was detected.

\section{Investigation}

1) Biochemical parameters were as follows: Liver function tests showed total serum bilirubin $-7 \mathrm{mg} / \mathrm{dl}$, direct bilirubin $5.4 \mathrm{mg} / \mathrm{dl}$, SGOT (81 U/l), SGPT-(91 $\mathrm{U} / \mathrm{l})$ and serum alkaline phosphatase-(1073 U/l).

2) Plain X-ray abdomen was normal. Ultra-sonography showed mild hepatomegaly with normal echo texture and a homogenous echogenic mass $7 \times 6 \mathrm{~cm}$ in connection with the common bile duct. The mass was reported as choledochal cyst (Figure 1).

3) Abdominal C.T.S showed, a well-defined hypodense mass is seen in the right hypochondrial region mainly at the liver helium, it measures about $10 \times 7$ $\times 6 \mathrm{~cm}$. Suggestive choledochal cysts (Figure 2).

\section{Treatments}

The patient was explored through a right subcostal incision. Exploration revealed 


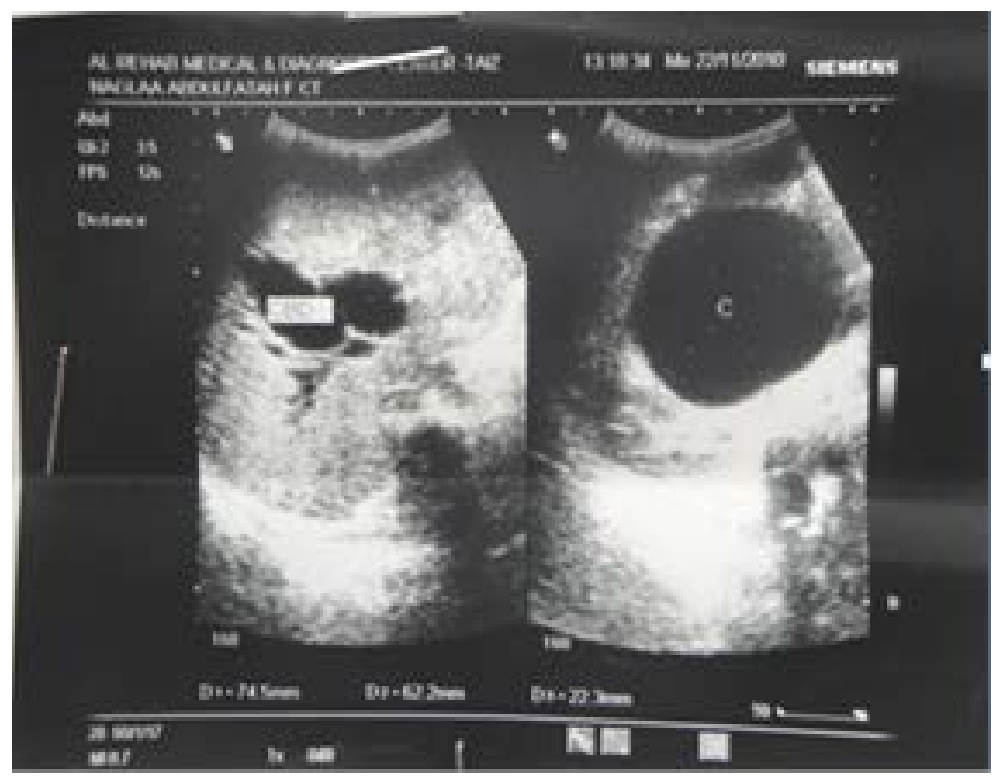

Figure 1. Ultra-sonography showed mild hepatomegaly with normal echo texture and a homogenous echogenic mass of $7 \times 6 \mathrm{~cm}$ in connection with the common bile duct.

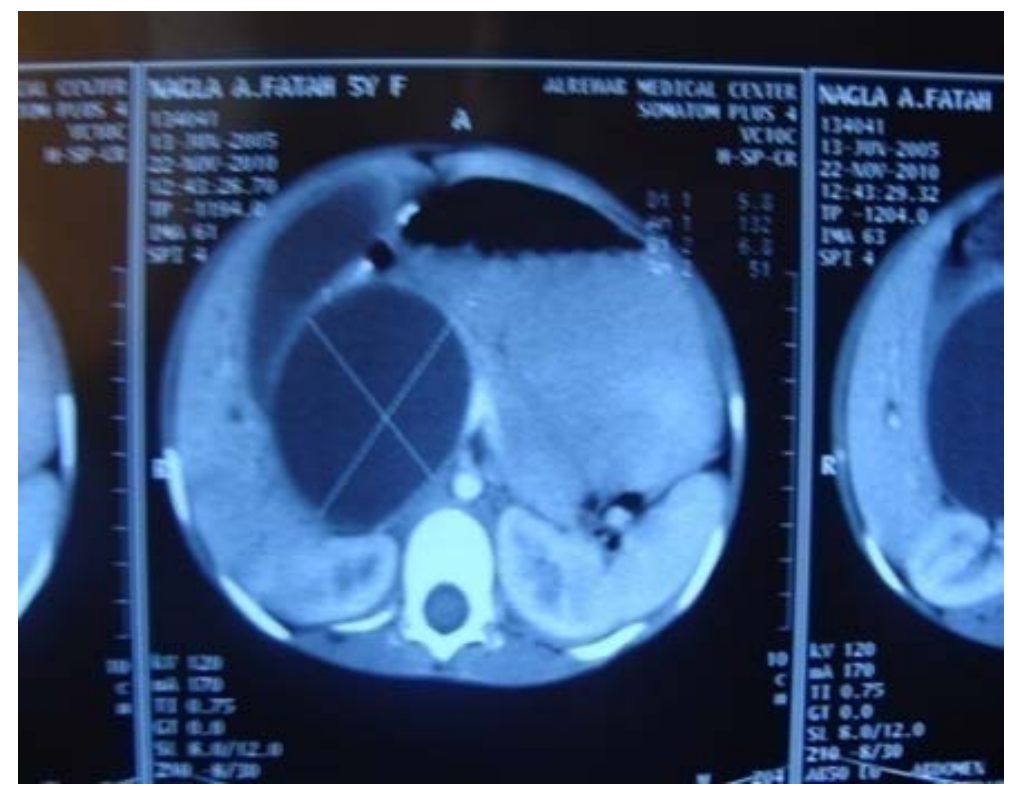

Figure 2. Abdominal C.T S showed choledochal cysts.

type I choledochal cyst (Figure 3). Cholecystectomy, cyst excision and Roux-en-Y hepaticojejunostomy were done. The patient tolerated the surgery well. On 10 the post-operative day liver function tests were repeated. Total serum bilirubin was found to be $3.1 \mathrm{mg} / \mathrm{dl}$, direct bilirubin $1.6 \mathrm{mg} / \mathrm{dl}$, SGOT (19 U/l), SGPT (28 U/l) and serum alkaline phosphatase $(820 \mathrm{U} / \mathrm{l})$. Repeat ultrasound showed a normal liver without any evidence of subphrenic collection.

\section{Discussion}

The term choledochal cyst refers to a spectrum of congenital biliary tract disorders 


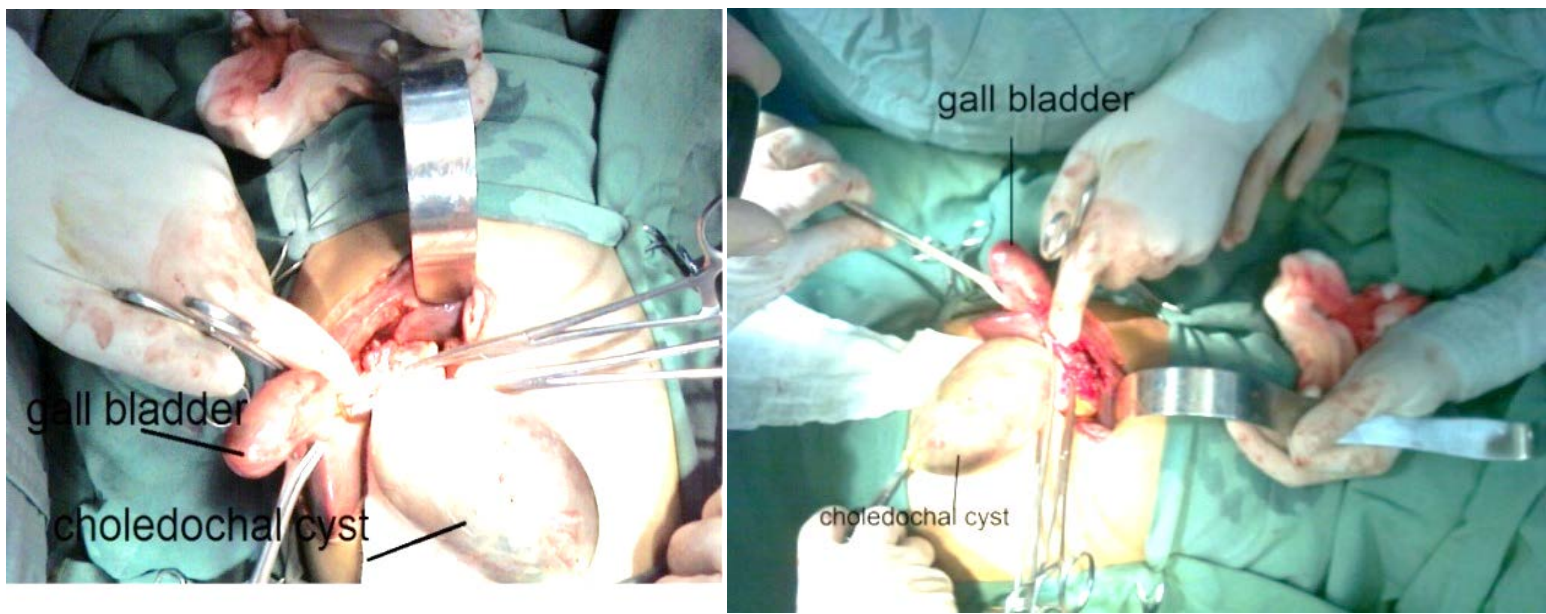

Figure 3. Intraoperative findings type I choledochal cyst.

Table 1. Cyst type: Alonso-Lej/Todani modification.

\begin{tabular}{|c|c|c|c|c|c|c|}
\hline Type [4] & Description & $\begin{array}{l}\text { Johns Hopkins; } \\
\text { [2] USA }\end{array}$ & $\begin{array}{l}\text { Northwestern; } \\
\text { [5] USA }\end{array}$ & $\begin{array}{l}\text { Hannover; } \\
\text { [6] Germany }\end{array}$ & $\begin{array}{l}\text { Kyushu; } \\
\text { [7] Japan }\end{array}$ & $\begin{array}{l}\text { Banaras; } \\
\text { [8] India }\end{array}$ \\
\hline $\begin{array}{c}\text { Type I } \\
\text { (choledochal cyst) }\end{array}$ & $\begin{array}{c}\text { Cystic (a) fusiform (b), or saccular (c) } \\
\text { extrahepatic biliary dilatation }\end{array}$ & $21(50 \%)$ & $\begin{array}{c}14-\mathrm{IA}(67 \%) \\
7-\mathrm{IB}(33 \%)\end{array}$ & $7(54 \%)$ & $26(57 \%)$ & $7(70 \%)$ \\
\hline Type II & Extrahepatic biliary diverticulum & $1(2 \%)$ & & $1(8 \%)$ & $0(0 \%)$ & $0(0 \%)$ \\
\hline $\begin{array}{c}\text { Type III } \\
\text { (choledochocele) }\end{array}$ & $\begin{array}{l}\text { Dilatation of extrahepatic } \\
\text { intraduodenal libiary tree }\end{array}$ & $2(5 \%)$ & & $1(0 \%)$ & $2(5 \%)$ & $0(0 \%)$ \\
\hline Type IV & & $14(33 \%)$ & & $2(15 \%)$ & $17(37 \%)$ & $3(30 \%)$ \\
\hline $\mathrm{A}$ & $\begin{array}{l}\text { Intrahepatic and extrahepatic } \\
\text { saccular/cystic dilatation }\end{array}$ & & & & & \\
\hline B & Multiple extrahepatic cysts & & & & & \\
\hline Type V (Caroli’s) & Intrahepatic biliary cyst & $4(10 \%)$ & & $2(15 \%)$ & $1(2 \%)$ & $0(0 \%)$ \\
\hline
\end{tabular}

that were previously grouped under the name idiopathic dilatation of the common bile duct. Alonso-Lej classified the choledochal cysts into three types which was subsequently modified by Todani et al. in 1977 (Table 1) [2]. The latter is the currently most commonly used classification. A type I cyst is a fusiform dilatation of the common bile duct. An isolated diverticulum protruding from the wall is considered a type II choledochal cyst. A type III choledochal cyst is also known as a choledochocele because it arises in the intraduodenal portion of the common bile duct. Multiple dilatations of the intrahepatic and extrahepatic bile ducts are considered type IVA, while type IVB involves exclusively the extrahepatic bile ducts. Type $\mathrm{V}$ is also known as Caroli's disease which involves multiple intrahepatic bile duct dilatation.

The etiology of choledochal cysts is unproven. An anomalous pancreaticobiliary junction resulting in an unusually long common channel has been suggested to result in antenatal pancreaticobiliary reflux leading to biliary stasis and dilatation [6]. Most choledochal cysts occur in women. Adults with initial ma- 
nifestation of choledochal cysts usually have non-specific right upper quadrant symptoms, jaundice, pancreatitis or cholangitis [7]. A palpable mass, which is a common presentation in children, is rare. In $80 \%$ of the cases the diagnosis is made before the age of 10. Diagnosis can be made by ultrasonography, CT-scan, endoscopic retrograde cholangiopancreatography (ERCP) and MRCP. Ultrasonography remains the most useful initial method of evaluating biliary tract abnormalities. CT-scan can be used to confirm the diagnosis [8]. In the case presented, 2 important investigations were done. Ultrasonography was performed as initial screening method, CT-scan to establish the diagnosis. The treatment of a choledochal cyst has changed. In the past, a cysto-jejunostomy was the standard procedure. Currently, excision of the cyst and reconstruction by hepato-jejunostomy is the standard therapy [9]. The two basic treatments of choledochal cysts are cyst enterostomy and cyst excision with hepaticojejunostomy. Cyst enterostomy is technically easier but is associated with late complications including anastomotic stricture, biliary calculi associated with stasis, recurrent cholangitis and malignant degeneration of the retained cyst wall. We successfully managed our patient with choledochal cyst by cyst excision and Roux-en-Y hepaticojejunostomy. The procedure of cyst excision decreases the risk of biliary stasis and the chances of developing cholangiocarcinoma, the reported incidence for which is in the range of $9 \%$ to $28 \%$ [2] [10].

\section{Conclusion}

The recurrent cholangitis, pancreatitis and malignant diseases associated with choledochal cysts mandate early diagnosis and definitive surgical management. Surgeons currently agree that all patients require complete cyst excision and Roux-en-Y hepaticojejunostomy.

\section{Conflicts of Interest}

The authors declare no conflicts of interest.

\section{References}

[1] de Vries, J.S., de Vries, S., Aronson, D.C., et al. (2002) Choledochal Cysts: Age of Presentation, Symptoms, and Late Complications Related to Todani's Classification. Journal of Pediatric Surgery, 37, 568-1573. https://doi.org/10.1053/jpsu.2002.36186

[2] Todani, T., Yosuhiro, W., Narasue, M., et al. (1977) Congenital Bile Duct Cysts: Classification, Operative Procedures and Review of 37 Cases Including Cancer Arising from Choledochal Cyst. American Journal of Surgery, 134, 263-269. https://doi.org/10.1016/0002-9610(77)90359-2

[3] Kim, M.J., Han, S.J., Yoon, C.S., Kim, J.H., Oh, J.T., Chung, K.S. and Yoo, H.S. (2002) Using MR Cholangiopancreatography to Reveal Anomalous Pancreaticobiliary Ductal Union in Infants and Children with Choledochal Cysts. American Journal of Roentgenology, 179, 209-214. https://doi.org/10.2214/ajr.179.1.1790209

[4] Kobayashi, S., Asano, T., Yamasaki, M., Kenmochi, T., Nakagohri, T. and Ochiai, T. (1999) Risk of Bile Duct Carcinogenesis after Excision of Extrahepatic Bile Ducts in Pancreaticobiliary Maljunction. Surgery, 126, 939-944. 
https://doi.org/10.1016/S0039-6060(99)70036-X

[5] Blumgart, L.H., et al. (2007) Surgery of the Liver and Biliary Tract and Pancreas. 4th Edtion, Vol II. Saunders, Philadelphia, 915-1838.

[6] Ono, J., Sakoda, K. and Akita, H. (1982) Surgical Aspects of Cystic Dilatation of the Bile Duct: An Anomalous Junction of Pancreaticobiliary Junction. Annals of Surgery, 195, 203-208. https://doi.org/10.1097/00000658-198202000-00014

[7] Hernadez, M.T., Rivera-Perez, V.S. and Hermosillo-Sandoval, J.M. (2007) Adult Choledochal Cyst. American Journal of Surgery, 193, 221-222.

https://doi.org/10.1016/j.amjsurg.2006.09.011

[8] Weyant, M.J., Maluccio, M.A., Bertagnolli, M.M. and Daly, J.M. (1998) Choledochal Cysts in Adults: A Report of Two Cases and Review of the Literature. American Journal of Gastroenterology, 93, 2580-2583. https://doi.org/10.1111/j.1572-0241.1998.00633.x

[9] Lipsett, P.A. and Pitt, H.A. (2003) Surgical Treatment of Choledochal Cysts. Hepatobiliary and Pancreatic Surgery, 10, 352-359.

https://doi.org/10.1007/s00534-002-0797-4

[10] Wiserman, K., Buczkowski, A.K. and Chung, S.W. (2005) Epidemiology, Presentation, Diagnosis and Outcomes of Choledochal Cysts in Adults in an Urban Environment. American Journal of Surgery, 189, 527-331.

https://doi.org/10.1016/j.amjsurg.2005.01.025 